\title{
Intake of Freshwater Fish and Associated Fatty Acids and Risk of Breast Cancer
}

\author{
Chang-Ming Gao ${ }^{1 *}$, Jian-Hua Ding ${ }^{1}$, Su-Ping Li ${ }^{1}$, Yan-Ting Liu ${ }^{1}$, Jin-Hai Tang ${ }^{1 *}$, \\ Kazuo Tajima ${ }^{2}$
}

\begin{abstract}
To investigate the association between intake of freshwater fish and their fatty acids and the risk of breast cancer in Chinese women, we conducted a case-control study with 669 cases and 682 population-based controls in Jiangsu Province of China. A structured questionnaire was used to elicit detailed information. Unconditional logistic regression analysis was performed to calculate odds ratios (ORs) and 95\% confidence intervals (CIs). Total freshwater fish intake was linked to decrease in the adjusted OR for breast cancer, but without dose-dependence. Analyses by freshwater fish species showed that consumption of black carp and silver carp was inversely related to breast cancer risk, with adjusted-ORs for the highest intake category of black carp $(\geq 500 \mathrm{~g} / \mathrm{month})$ of 0.54 $\left(95 \% \mathrm{CI}=0.33-0.92 ; P_{\text {trend }}<0.002\right)$ and for silver carp ( $\left.\geq 1000 \mathrm{~g} / \mathrm{month}\right)$ of $0.19\left(95 \% \mathrm{CI}=\mathbf{0 . 1 1 - 0 . 3 3} ; P_{\text {trend }}<0.001\right)$. In contrast, consumption of crucian carp was positively related to breast cancer risk, with an adjusted OR for the highest intake category $(\geq 1000 \mathrm{~g} / \mathrm{month})$ of $6.09\left(95 \% \mathrm{CI}=3.04-12.2 ; P_{\text {trend }}<0.001\right)$. Moderate intakes of SFA, PUFA, n3-PUFA and n6-PUFA from freshwater fish may decrease the risk of breast cancer among premenopausal women. The findings of this study suggest that intake of freshwater fish and their fatty acids may modify risk of breast cancer, and that different species of freshwater fish could have a different actions on breast cancer risk. Future epidemiologic studies are needed to know the effects of freshwater fish intake on breast cancer risk and the cause of these effects.
\end{abstract}

Keywords: Freshwater fish - fatty acids - breast cancer - Chinese

Asian Pac J Cancer Prev, 15 (18), 7879-7884

\section{Introduction}

Breast cancer constitutes the most common cancer in women and is an important public health concern worldwide. Although the incidence rate of breast cancer in China is lower than those in Western countries, there has been a marked increase in recent years (Parkin et al., 2005; Yang et al., 2005). In the past few decades, epidemiological studies (Brennan et al., 2010; Lambrechts et al., 2011; Gao et al., 2013) have suggested that a healthy diet and lifestyle is critical factor for the prevention of breast cancer. Many authors have analysed relationship between the fish intake and the risk of breast cancer, however the results have been inconsistent (Wirfalt et al., 2002; Terry et al., 2003; Hirose et al., 2006; Engeset et al., 2006; Brustad et al., 2007; Kim et al., 2009; Sala-Vila and Calder, 2011; Zheng et al., 2013).

Most previous studies on the association of breast cancer risk with fish did not analyze freshwater and marine fish separately. Dai et al. (2002) and Bao et al. (2012) found that intake of freshwater fish was related to an increased risk of breast cancer. Freshwater fish is one of the staples of Chinese diet, especially in the non-littoral of China. To evaluate the relationship between intakes of freshwater fish and their fatty acids with breast cancer risk, we conducted this case-control study in Jiangsu Province, China.

\section{Materials and Methods}

\section{Study subjects}

We recruited breast cancer cases using data of the Cancer Registries in Taixing, Wuxi, Jintan and Huian Cities of Jiangsu Province of China, and also recruited cases who visited Jiangsu Province Cancer Hospital from these cities from June 2004 to December 2007. All cases were histopathologically diagnosed as having a primary breast cancer. Physicians at the hospital asked eligible cases to participate in our study, and doctors or nurses interviewed the participants after obtaining informed consent. Population-based controls were selected from healthy residents in eleven villages or towns of Taixing, Wuxi, Jintan and Huian Cities. Doctors of the public health centers randomly selected one or two controls

${ }^{1}$ Division of Epidemiology, Jiangsu Province Institute of Cancer Research, Nanjing, Jiangsu Province, China, ${ }^{2}$ Department of Public Health and Occupational Medicine, Mie University Graduate School of Medicine, Edobashi Tsu, Mie, Japan *For correspondence:gaocm888@126.com 
for each case, after matching for ethnicity and age within 2 years using the records of residents at the local governmental office, and then asked eligible residents for their participation. Interviews were performed as for the cancer cases. Total 669 cases and 682 controls completed interview. The ethics committee of Jiangsu Province Institute of Cancer Research approved this study.

\section{Data collection}

All participants completed an in-person interview that used a structured questionnaire. Dietary intakes were assessed using an 83-item food frequency questionnaire (FFQ), capturing $90 \%$ of food intake and covering nutrients constituting up to $90 \%$ of the nutrient intake in urban and rural areas of Jiangsu province (Wang et al., 2003). Each participant was asked about the frequency of a specific food that was eaten, followed by a question on the amount typically consumed. The FFQ listed 5 species of freshwater fish, including black carp (Mylopharyngodon piceus), finless eel (Monopterus albus), bream (Parabramis pekinensis), crucian carp (Crassius auratus) and silver carp (Hypopthalmichthys motitrix). Intakes of the fat and fatty acids (including total fatty acid, SFA, MUFA, PUFA, n3-PUFA and n6-PUFA) were calculated according to consumption of these freshwater fish, with Standard Food Composition Tables for China. (Yang et al., 2002).

\section{Data analysis}

Odds ratios (ORs) were used to measure the association of breast cancer risk with intakes of freshwater fish and their fatty acids. Unconditional logistic regression from the statistical package SAS were used to obtain maximum likelihood estimates of the ORs and their $95 \%$ confidence intervals (CIs), and used to the line trend test of ORs. All ORs were adjusted by age, status of marriage and menstruation, age of menarche and menopause, childbirth, body mass index (BMI), family history of breast cancer, income/month, status of the smoking and alcohol drinking, meats consumption, and intakes of the fruit and vegetables. Quarter distributions of intakes of the fat and fatty acids from freshwater fish among controls were used to categorize the variables.

\section{Results}

Table 1 shows comparisons of cases and controls on demographic factors, physiological and reproductive characteristics, and other known risk factors of breast cancer. Compared with controls, cases were younger at menarche and older at menopause. Cases were more likely to have a higher income, a family history of breast cancer among first-degree relatives. The statistically significant differences between cases and controls were observed for childbirth, status of the smoking and alcohol drinking, and usual consumption of the meats and fruit and vegetables. All of these variables were considered as potential confounders and adjusted for in subsequent analyses.

Data for associations between intakes of freshwater fish and breast cancer risk are presented in Table 2. As compared with women who never intakes of all freshwater fish, the adjusted OR for breast cancer among consumers of freshwater fish was 0.25 (95\%CI: 0.11-0.57). Analyses by freshwater fish species showed that intakes of the black carp, finless eel, bream and silver carp significantly lowered the adjusted-ORs for breast cancer, the adjustedORs and their 95\%CIs were $0.66(0.51-0.84)$ for black carp, 0.47 (0.36-0.61) for finless eel, 0.54 (0.41-0.72) for bream and $0.46(0.35-0.60)$ for silver carp, respectively.

Table 3 shows the dose-response relationship between the consumption of freshwater fish and the breast cancer risk. Among all study subjects, after adjusting for potential confounders, the ORs for breast cancer were significantly decreased with increasing consumption of the black carp and silver carp, with a statistically significant dose-response relation ( $P$ for trend $=0.002$ and $<0.001$, respectively). Reduced risk was also related to high consumption of finless eel ( $P$ for trend $<0.001$ ), but the adjusted-OR of the highest intake category ( $\geq 500 \mathrm{~g} / \mathrm{month}$ ) was not statistically significant. With regard to intake of bream, compared with the never intake of bream, the second and the third intake categories all had a significant decreased adjusted-OR, but the adjusted-OR of the highest intake category ( $\geq 1000 \mathrm{~g} / \mathrm{month}$ ) showed a clear increase

Table 1. Comparison of Cases and Controls by Selected Descriptive Characteristics

\begin{tabular}{|c|c|c|c|c|}
\hline & \multicolumn{2}{|c|}{ Cases $(n=669)$ Controls $(n=682)$} & $\chi^{2}$ & $P$ \\
\hline \multicolumn{3}{|c|}{ Age at menarche (years) } & 8.11 & 0.004 \\
\hline$\geq 14$ & $479(73.1)$ & $541(79.3)$ & & \\
\hline$\leq 13$ & $180(26.9)$ & $141(20.7)$ & & \\
\hline \multicolumn{3}{|c|}{ Age at menopause (years) } & 29.21 & 0.001 \\
\hline$\leq 50$ & $216(60.0)$ & $305(78.2)$ & & \\
\hline$<50$ & $144(40.0)$ & $85(21.8)$ & & \\
\hline \multicolumn{3}{|l|}{ Childbirth } & 4.14 & 0.042 \\
\hline Never & $25(3.7)$ & $13(1.9)$ & & \\
\hline Have & $644(96.3)$ & $669(98.1)$ & & \\
\hline \multicolumn{3}{|l|}{ BMI } & 4.88 & 0.087 \\
\hline$<22$ & $225(33.63)$ & $244(35.78)$ & & \\
\hline $22-24.9$ & $256(38.27)$ & $282(41.35)$ & & \\
\hline$\geq 25$ & $188(28.10)$ & $156(22.87)$ & & \\
\hline \multicolumn{3}{|c|}{ Family history of breast cancer } & 15.31 & 0.001 \\
\hline No & $638(95.22)$ & $674(98.83)$ & & \\
\hline Have & $32(4.78)$ & $8(1.17)$ & & \\
\hline \multicolumn{3}{|l|}{ Income/month } & 30.79 & 0.001 \\
\hline Low & $171(25.56)$ & $259(37.98)$ & & \\
\hline Middle & $230(34.38)$ & $232(34.02)$ & & \\
\hline High & $268(40.06)$ & $191(28.01)$ & & \\
\hline \multicolumn{3}{|l|}{ Smoking status } & 8.07 & 0.018 \\
\hline Never & $653(97.61)$ & $677(99.27)$ & & \\
\hline Current & $6(0.90)$ & $4(0.59)$ & & \\
\hline Ever & $10(1.49)$ & $1(0.15)$ & & \\
\hline \multicolumn{3}{|c|}{ Alcohol drinking status } & 7.50 & 0.023 \\
\hline Never & $637(95.22)$ & $662(97.07)$ & & \\
\hline Current & $18(2.69)$ & $17(2.49)$ & & \\
\hline Ever & $14(2.09)$ & $3(0.44)$ & & \\
\hline \multicolumn{3}{|c|}{ Meats intake (g/month) } & 9.44 & 0.024 \\
\hline$<500$ & $158(23.62)$ & $176(25.81)$ & & \\
\hline $500-999$ & $202(30.19)$ & $212(31.09)$ & & \\
\hline $1000-1499$ & $105(15.70)$ & $133(19.50)$ & & \\
\hline$\geq 1500$ & $204(30.49)$ & $161(23.61)$ & & \\
\hline \multicolumn{3}{|c|}{ Fruits intake (g/month) } & 8.21 & 0.042 \\
\hline$<500$ & $80(11.96)$ & $88(12.90)$ & & \\
\hline $500-999$ & $145(21.67)$ & $151(22.14)$ & & \\
\hline 1000-1499 & $78(11.66)$ & $112(16.42)$ & & \\
\hline$\geq 1500$ & $366(54.71)$ & $331(48.53)$ & & \\
\hline \multicolumn{3}{|c|}{ Vegetables intake (g/month) } & 45.59 & 0.001 \\
\hline$<5000$ & $240(35.87)$ & $311(45.60)$ & & \\
\hline 5000-9999 & $210(31.39)$ & $251(36.80)$ & & \\
\hline$\geq 10000$ & $219(32.73)$ & $120(17.59)$ & & \\
\hline
\end{tabular}


(1.92,95\% CI: 0.92-3.97). A significant increased trend in the risk of breast cancer with increasing consumption of crucian carp was observed $(P$ for trend $<0.001)$. Compared with the never intake of crucian carp, the highest intake category $(\geq 1000 \mathrm{~g} / \mathrm{month})$ had a significant increased adjusted-OR (6.09, 95\%CI: 3.04-12.19). Increasing consumption of the total freshwater fish decreased ORs for breast cancer, but the test for linear trend was not statistically significant. In analyses by menopause status, the similar effect of freshwater fish intake was observed in both post- and premenopausal women.

Table 4 shows the dose-response relationship between the consumption of fat and fatty acids from intakes of freshwater fish and the breast cancer risk. Among all study subjects, compared with the lowest quarter of intakes of the fat and fatty acids (including total fatty acid, SFA, MUFA, PUFA, n3-PUFA and n6-PUFA), women in other quarters all had a decreased adjusted-OR for breast cancer, but the tests for linear trend were not statistically significant (all $P$ for trend $>0.05$ ). Among premenopausal

Table 2. Freshwater Fish Intake and Breasd Cancer Risk

\begin{tabular}{|c|c|c|c|c|c|}
\hline Fish intake & & $\begin{array}{l}\text { Cases } \\
\mathrm{n}(\%)\end{array}$ & $\begin{array}{c}\text { Controls } \\
\mathrm{n}(\%)\end{array}$ & $\begin{array}{c}\text { Crude OR } \\
(95 \% \mathrm{CI})\end{array}$ & $\begin{array}{c}\text { Adjusted OR* } \\
(95 \% \mathrm{CI})\end{array}$ \\
\hline \multirow[t]{2}{*}{ Black carp } & Never eaten & $364(54.4)$ & $340(49.9)$ & 1.00 & 1.00 \\
\hline & Eaten & $305(45.6)$ & $342(50.1)$ & $0.83(0.67-1.03)$ & $0.66(0.51-0.84)$ \\
\hline \multirow{2}{*}{ Finless eel } & Never eaten & $378(56.5)$ & $273(40.0)$ & 1.00 & 1.00 \\
\hline & Eaten & $291(43.5)$ & $409(60.0)$ & $0.51(0.41-0.64)$ & $0.47(0.36-0.61)$ \\
\hline \multirow[t]{2}{*}{ Bream } & Never eaten & $233(34.8)$ & $174(25.5)$ & 1.00 & 1.00 \\
\hline & Eaten & $436(65.2)$ & $508(74.5)$ & $0.64(0.51-0.81)$ & $0.54(0.41-0.72)$ \\
\hline \multirow[t]{2}{*}{ Crucian carp } & Never eaten & $113(16.9)$ & $131(19.2)$ & 1.00 & 1.00 \\
\hline & Eaten & $556(83.1)$ & $551(80.8)$ & $1.17(0.89-1.54)$ & $0.95(0.69-1.31)$ \\
\hline \multirow[t]{2}{*}{ Silver carp } & Never eaten & $278(41.6)$ & $146(21.2)$ & 1.00 & 1.00 \\
\hline & Eaten & $391(58.5)$ & $536(78.6)$ & $0.38(0.30-0.49)$ & $0.46(0.35-0.60)$ \\
\hline \multirow{2}{*}{ All freshwater fish } & Never eaten & $31(4.6)$ & $9(1.3)$ & 1.00 & 1.00 \\
\hline & Eaten & $638(95.4)$ & $673(98.7)$ & $0.28(0.13-0.58)$ & $0.25(0.11-0.57)$ \\
\hline
\end{tabular}

*Adjusted by age, status of marriage and menstruation, age of menarche and menopause, childbirth; BMI, family history of breast cancer, income/month, status of smoking and alcohol drinking, intake of meats and fruit and vegetables

Table 3. Freshwater Fish Consumption and Breasd Cancer Risk

\begin{tabular}{|c|c|c|c|c|c|c|}
\hline \multirow{2}{*}{$\begin{array}{l}\text { Fish intake } \\
\text { (g/month) }\end{array}$} & \multicolumn{2}{|c|}{ Total } & \multicolumn{2}{|c|}{ Postmenopausal } & \multicolumn{2}{|c|}{ Premenopausal } \\
\hline & Case/control (n) & OR $(95 \% \mathrm{CI})$ & Case/control (n) & OR $(95 \% \mathrm{CI})$ & Case/control (n) & OR $(95 \% \mathrm{CI})$ \\
\hline \multicolumn{7}{|l|}{$\overline{\text { Black carp }}$} \\
\hline 0 & $364 / 340$ & 1.00 & $194 / 197$ & 1.00 & $170 / 143$ & 1.00 \\
\hline $1-499$ & $259 / 294$ & $0.66(0.51-0.86)$ & $144 / 165$ & $0.77(0.54-1.11)$ & $115 / 129$ & $0.59(0.40-0.87)$ \\
\hline$\geq 500$ & $46 / 48$ & $0.54(0.33-0.92)$ & $23 / 28$ & $0.42(0.20-0.89)$ & $23 / 20$ & $0.66(0.31-1.41)$ \\
\hline$P$ for trend & & 0.002 & & 0.038 & & 0.022 \\
\hline \multicolumn{7}{|l|}{ Finless eel } \\
\hline 0 & $378 / 273$ & 1.00 & $210 / 153$ & 1.00 & $168 / 120$ & 1.00 \\
\hline $1-499$ & $268 / 391$ & $0.47(0.36-0.61)$ & $141 / 226$ & $0.41(0.29-0.59)$ & $127 / 166$ & $0.59(0.41-0.86)$ \\
\hline$\geq 500$ & $23 / 18$ & $0.51(0.23-1.11)$ & $10 / 12$ & $0.50(0.17-1.46)$ & $13 / 6$ & $0.67(0.20-2.18)$ \\
\hline$P$ for trend & & $<0.001$ & & $<0.001$ & & 0.023 \\
\hline \multicolumn{7}{|l|}{ Bream } \\
\hline 0 & $233 / 174$ & 1.00 & $120 / 101$ & 1.00 & $113 / 73$ & 1.00 \\
\hline $1-499$ & $288 / 403$ & $0.52(0.39-0.69)$ & $149 / 226$ & $0.50(0.34-0.74)$ & $139 / 177$ & $0.53(0.35-0.81)$ \\
\hline $500-999$ & $71 / 91$ & $0.37(0.23-0.60)$ & $46 / 53$ & $0.41(0.21-0.80)$ & $25 / 38$ & $0.30(0.14-0.63)$ \\
\hline$\geq 1000$ & $77 / 14$ & $1.92(0.92-3.97)$ & $46 / 10^{\prime}$ & $1.92(0.73-5.01)$ & $31 / 4$ & $2.11(0.62-7.21)$ \\
\hline$P$ for trend & & 0.251 & & 0.574 & & 0.240 \\
\hline \multicolumn{7}{|l|}{ Crucian carp } \\
\hline 0 & $113 / 131$ & 1.00 & $53 / 63$ & 1.00 & $60 / 68$ & 1.00 \\
\hline $1-499$ & $281 / 388$ & $0.79(0.56-1.10)$ & $150 / 239$ & $0.72(0.44-1.18)$ & $131 / 149$ & $1.01(0.61-1.66)$ \\
\hline $500-999$ & $136 / 138$ & $1.02(0.66-1.56)$ & $78 / 78$ & $1.17(0.62-2.20)$ & $58 / 60$ & $1.11(0.59-2.08)$ \\
\hline$\geq 1000$ & $139 / 25$ & $6.09(3.04-12.19)$ & $80 / 10^{\prime}$ & $19.67(5.76-67.23)$ & $59 / 15$ & $2.96(1.07-8.17)$ \\
\hline$P$ for trend & & $<0.001$ & & $<0.001$ & & 0.003 \\
\hline \multicolumn{7}{|l|}{ Silver carp } \\
\hline 0 & $278 / 146$ & 1.00 & $155 / 63$ & 1.00 & $123 / 83$ & 1.00 \\
\hline $1-499$ & $273 / 322$ & $0.47(0.35-0.64)$ & $138 / 182$ & $0.32(0.21-0.49)$ & $135 / 140$ & $0.70(0.46-1.07)$ \\
\hline $500-999$ & $85 / 145$ & $0.39(0.26-0.58)$ & $45 / 92$ & $0.53(0.30-0.93)$ & $40 / 53$ & $0.84(0.47-1.52)$ \\
\hline$\geq 1000$ & $33 / 69$ & $0.19(0.11-0.33)$ & $23 / 53$ & $0.14(0.07-0.29)$ & $10 / 16$ & $0.35(0.14-0.92)$ \\
\hline$P$ for trend & & $<0.001$ & & $<0.001$ & & 0.036 \\
\hline \multicolumn{7}{|c|}{ All freshwater fish } \\
\hline $1-499$ & $192 / 173$ & 1.00 & $99 / 90$ & 1.00 & $93 / 83$ & 1.00 \\
\hline $500-999$ & $158 / 227$ & $0.60(0.44-0.83)$ & $81 / 134$ & $0.49(0.31-0.78)$ & $77 / 93$ & $0.81(0.50-1.31)$ \\
\hline $1000-1499$ & $113 / 119$ & $0.65(0.44-0.96)$ & $55 / 66$ & $0.57(0.32-1.02)$ & $58 / 53$ & $0.91(0.51-1.62)$ \\
\hline$\geq 1500$ & $206 / 163$ & $0.85(0.58-1.26)$ & $126 / 100$ & $0.97(0.57-1.66)$ & $80 / 63$ & $0.85(0.46-1.55)$ \\
\hline$P$ for trend & & 0.292 & & 0.992 & & 0.738 \\
\hline
\end{tabular}

*ORs were adjusted by age, status of marriage and menstruation, age of menarche and menopause, childbirth; BMI, family history of breast cancer, income/month, status of smoking and alcohol drinking, intake of meats and fruit and vegetables 
Table 4. Consumption of the Fat and Fatty Acid from Freshwater Fish and Breasd Cancer Risk

\begin{tabular}{|c|c|c|c|c|c|c|}
\hline \multirow{2}{*}{$\begin{array}{c}\text { Fatty acids } \\
\text { (g/month) }\end{array}$} & \multicolumn{2}{|c|}{ Total } & \multicolumn{2}{|c|}{ postmenopausal } & \multicolumn{2}{|c|}{ premenopausal } \\
\hline & Case/control (n) & OR $(95 \% \mathrm{CI})^{*}$ & Case/control (n) & OR $(95 \% \mathrm{CI})^{*}$ & Case/control (n) & OR $(95 \% \mathrm{CI})^{*}$ \\
\hline \multicolumn{7}{|l|}{$\overline{\text { Fat }}$} \\
\hline $0-16.2$ & $175 / 174$ & 1.00 & $92 / 92$ & 1.00 & $83 / 82$ & 1.00 \\
\hline $16.3-29.7$ & $139 / 168$ & $0.78(0.55-1.10)$ & $74 / 102$ & $0.63(0.39-1.02)$ & $65 / 66$ & $1.04(0.62-1.75)$ \\
\hline $29.8-51.6$ & $132 / 172$ & $0.60(0.42-0.87)$ & $57 / 89$ & $0.43(0.25-0.75)$ & $75 / 83$ & $0.91(0.54-1.53)$ \\
\hline$\geq 51.7$ & $223 / 168$ & $0.95(0.64-1.42)$ & $138 / 107$ & $1.03(0.61-1.76)$ & $85 / 61$ & $0.85(0.45-1.60)$ \\
\hline$P$ for trend & & 0.445 & & 0.527 & & 0.981 \\
\hline \multicolumn{7}{|l|}{ Fatty acid } \\
\hline $0-11.95$ & $174 / 171$ & 1.00 & $92 / 92$ & 1.00 & $82 / 79$ & 1.00 \\
\hline $11.96-21.1$ & $136 / 170$ & $0.73(0.52-1.04)$ & $71 / 102$ & $0.62(0.38-1.00)$ & $65 / 68$ & $0.99(0.58-1.67)$ \\
\hline $21.2-37.6$ & $134 / 171$ & $0.61(0.42-0.88)$ & $61 / 89$ & $0.47(0.27-0.82)$ & $73 / 82$ & $0.86(0.52-1.51)$ \\
\hline$\geq 37.6$ & $225 / 170$ & $0.88(0.89-1.30)$ & $137 / 107$ & $0.97(0.57-1.65)$ & $88 / 63$ & $0.85(0.45-1.60)$ \\
\hline$P$ for trend & & 0.420 & & 0.603 & & 0.890 \\
\hline \multicolumn{7}{|l|}{ SFA } \\
\hline $0-3.85$ & $194 / 172$ & 1.00 & $103 / 96$ & 1.00 & $91 / 76$ & 1.00 \\
\hline $3.86-6.55$ & $129 / 172$ & $0.64(0.45-0.90)$ & $62 / 97$ & $0.57(0.35-0.92)$ & $67 / 75$ & $0.79(0.47-1.32)$ \\
\hline $6.56-11.7$ & $142 / 170$ & $0.57(0.40-0.82)$ & $72 / 93$ & $0.49(0.29-0.83)$ & $70 / 78$ & $0.73(0.43-1.24)$ \\
\hline$\geq 11.8$ & $204 / 168$ & $0.72(0.49-1.06)$ & $124 / 105$ & $0.78(0.46-1.31)$ & $80 / 63$ & $0.71(0.38-1.31)$ \\
\hline$P$ for trend & & 0.060 & & 0.289 & & 0.253 \\
\hline \multicolumn{7}{|l|}{ MUFA } \\
\hline $0-4.80$ & $176 / 173$ & 1.00 & $93 / 93$ & 1.00 & $83 / 80$ & 1.00 \\
\hline 4.9-8.9 & $145 / 169$ & $0.77(0.55-1.09)$ & $74 / 100$ & $0.63(0.39-1.02)$ & $71 / 69$ & $1.07(0.64-1.80)$ \\
\hline $9.0-15.4$ & $122 / 170$ & $0.54(0.37-0.78)$ & $55 / 91$ & $0.39(0.23-0.69)$ & $67 / 79$ & $0.78(0.45-1.34)$ \\
\hline$\geq 15.5$ & $226 / 170$ & $0.90(0.61-1.33)$ & $139 / 106$ & $1.05(0.61-1.78)$ & $87 / 64$ & $0.81(0.43-1.53)$ \\
\hline$P$ for trend & & 0.268 & & 0.525 & & 0.630 \\
\hline \multicolumn{7}{|l|}{ PUFA } \\
\hline $0-2.4$ & $182 / 184$ & 1.00 & $93 / 96$ & 1.00 & $89 / 88$ & 1.00 \\
\hline $2.45-4.2$ & $129 / 165$ & $0.74(0.52-1.05)$ & $67 / 104$ & $0.52(0.32-0.85)$ & $62 / 61$ & $1.20(0.70-2.04)$ \\
\hline $4.3-7.2$ & $128 / 164$ & $0.65(0.45-0.94)$ & $60 / 86$ & $0.52(0.30-0.88)$ & $68 / 78$ & $0.89(0.53-1.50)$ \\
\hline$\geq 7.3$ & $230 / 169$ & $0.98(0.67-1.45)$ & $141 / 104$ & $1.07(0.62-1.83)$ & $89 / 65$ & $1.00(0.55-1.81)$ \\
\hline$P$ for trend & & 0.873 & & 0.847 & & 0.981 \\
\hline \multicolumn{7}{|l|}{ n3-PUFA } \\
\hline $0-0.78$ & $176 / 171$ & 1.00 & $89 / 88$ & 1.00 & $87 / 83$ & 1.00 \\
\hline $0.79-1.35$ & $129 / 174$ & $0.69(0.48-0.97)$ & $68 / 109$ & $0.51(0.31-0.84)$ & $61 / 65$ & $1.04(0.61-1.78)$ \\
\hline $1.36-2.35$ & $133 / 166$ & $0.65(0.45-0.94)$ & $63 / 87$ & $0.54(0.31-0.92)$ & $70 / 79$ & $0.86(0.51-1.44)$ \\
\hline$\geq 2.36$ & $231 / 171$ & $0.95(0.64-1.40)$ & $141 / 106$ & $1.06(0.62-1.83)$ & $90 / 65$ & $0.92(0.50-1.70)$ \\
\hline$P$ for trend & & 0.841 & & 0.873 & & 0.976 \\
\hline \multicolumn{7}{|l|}{ n6-PUFA } \\
\hline $0-2.01$ & $174 / 170$ & 1.00 & $88 / 87$ & 1.00 & $86 / 83$ & 1.00 \\
\hline $2.02-3.591$ & $132 / 171$ & $0.73(0.51-1.03)$ & 70/106 & $0.54(0.33-0.89)$ & $62 / 65$ & $1.07(0.64-1.83)$ \\
\hline $3.592-6.20$ & $133 / 170$ & $0.63(0.44-0.90)$ & $62 / 92$ & $0.49(0.28-0.83)$ & $71 / 78$ & $0.89(0.53-1.49)$ \\
\hline$\geq 6.21$ & $230 / 171$ & $0.94(0.64-1.39)$ & $141 / 105$ & $1.04(0.60-1.79)$ & $89 / 66$ & $0.95(0.52-1.74)$ \\
\hline$P$ for trend & & 0.756 & & 0.973 & & 0.984 \\
\hline
\end{tabular}

*ORs were adjusted by age, status of marriage and menstruation, age of menarche and menopause, childbirth; BMI, family history of breast cancer, income/month, status of smoking and alcohol drinking, intake

women, there were significant reduction in breast cancer risk for the second and the third intake quartiles of the SFA, PUFA, n3-PUFA and n6-PUFA compared to the reference group who consumed the lowest quartile, but the adjusted ORs were not statistically significant in the highest intake quartile. Among premenopausal women, there were no significant association between intakes of the fat and fatty acids from freshwater fish and the risk of breast cancer.

\section{Discussion}

In this study, we analysed relationship between intakes of five common species of freshwater fish and the risk of breast cancer. We found that consumption of the black carp, finless eel, and silver carp were inversely related to breast cancer risk, whereas consumption of crucian carp was positively related to breast cancer risk.

Freshwater fish provide a healthy source of high-quality proteins, essential vitamins, minerals and polyunsaturated fatty acids. Humans ingest eicosapentaenoic acid (EPA) and docosahexaenoic acid (DHA) mainly through intake of fish. But, previous research also has shown that freshwater fish may have a high level of nocuous chemicals, such as methylmercury, polychlorinated dibenzo- $p$-dioxins, and dibenzofurans, organochlorine residues, and other contaminants (Dai et al., 2002; Watanabe et al., 2003; Hirunwatthanakul et al., 2006; Cheng et al., 2013; Eqani et al., 2013; Saengsawang et al., 2013; Wang et al., 2013; Lee et al., 2014), and some of them have been shown to be mutagens or animal carcinogens. Because contaminants and nutrients always coexist in freshwater fish, the risk 
from contaminants and the benefit from nutrients are also concomitant via freshwater fish consumption.

Wang et al. (2013) calculated the benefit-risk quotient of the EPA and DHA vs. persistent organic pollutants via intakes of freshwater fish from Taihu Lake of China. They found that to achieve the recommended EPA and DHA intake of $250 \mathrm{mg} / \mathrm{d}$ for a healthy adult, the intakes of most fish species from the lake can cause cancer and non-cancer risks. However, the fish consumption at the rates of $44.9 \mathrm{~g} / \mathrm{d}$ by Chinese would not lead to the risks for most of the fish species. Lee et al. (2014) measured seven organochlorine pesticides (OCPs) in river water of Yeongsan and Seomjin Rivers of Korea, and assessed the potential health risks of consuming OCPs from fish in the monitoring region by measuring the residual level of OCPs. They found that there is a high cancer risk associated with three OCPs. Thus, they indicated that individuals who consume large amounts of freshwater fish may be subject to a high risk of cancer. In our study, we found that when consumption of the bream and crucian carp were higher $(\geq 1000 \mathrm{~g} / \mathrm{month})$, the risk of breast cancer were clear increased. These results showed that the consumption of freshwater fish must be moderate.

Wang et al. (2013) found that the risk of consuming silver carp was generally lower than other freshwater fish species. In this study, we also found that consumption of silver carp was inversely related to breast cancer risk, whereas consumption of crucian carp was positively related to breast cancer risk. Our findings are consistent with results of Wang et al. Crucian carp is an omnivorous fish. Study results of Cheng et al. (2013) in Hong Kong showed that omnivorous fish accumulated higher concentrations of heavy metals from sediment in the pond or river than carnivorous fish. Zhuang et al. (2013) determined heavy metal accumulation in five carp species from two fishponds exposed to effluent waters from Dabaoshan mine of South China. They found that crucian carp (carassius auratus) accumulated the higher $\mathrm{Pb}, \mathrm{Cd}$, $\mathrm{Zn}$, and $\mathrm{Cu}$ in the intestine compared with other fish species. Thus, individuals who consume large amounts of crucian carp have higher risk of breast cancer, may be associated with the contaminated degree of crucian carp by heavy metals .

Kim et al. (2009) investigated the association between fatty fish and their fatty acids intake and the incidence of breast cancer in Korean women. They found that high consumption of fatty fish is associated with a reduced risk for breast cancer, and that the intake of $\omega$-3 fatty acids from fish is inversely associated with postmenopausal breast cancer risk. We also analysed relationship between the fat and fatty acids only from intakes of freshwater fish and the breast cancer risk. We found that moderate intakes of the SFA, PUFA, n3-PUFA and n6-PUFA from freshwater fish significantly decreased the risk of breast cancer among premenopausal women. Our results are partly similar to the finding of Kim et al. But we also found that the adjusted ORs were not statistically significant in the highest intake quartiles of the SFA, PUFA, n3PUFA and n6-PUFA compared with the reference group who consumed the lowest quartile. Although chemical contaminants and nutrients coexist in freshwater fish may partly explain the finding, further investigations into the dietary intake of OCPs or heavy metals and genetic factors will be important in clarifying the preventive effect of freshwater fish intake on breast cancer.

\section{References}

Bao PP, Shu XO, Zheng Y, et al (2012). Fruit, vegetable, and animal food intake and breast cancer risk by hormone receptor status. Nutr Cancer, 64, 806-19.

Brennan SF, Cantwell MM, Cardwell CR, et al (2010). Dietary patterns and breast cancer risk: a systematic review and meta-analysis. Am J Clin Nutr, 91, 1294-302.

Brustad M, Sandanger TM, Andersen V, Lund E (2007). POP exposure from fish liver consumption and risk of cancer- the Norwegian Women and Cancer Study. J Environ Monit, 9, 682-6.

Cheng Z, Chen KC, Li KB, et al (2013). Arsenic contamination in the freshwater fish ponds of Pearl River Delta: bioaccumulation and health risk assessment. Environ Sci Pollut Res Int, 20, 4484-95.

Dai Q, Shu XO, Jin F, et al (2002). Consumption of animal foods, cooking methods, and risk of breast cancer. Cancer Epidemiol Biomarkers Prev, 11, 801-8.

Engeset D, Alsaker E, Lund E, et al (2006). Fish consumption and breast cancer risk. the european prospective investigation into cancer and nutrition (EPIC). Int J Cancer, 119, 175-82.

Eqani SA, Malik RN, Cincinelli A, et al (2013). Uptake of organochlorine pesticides (OCPs) and polychlorinated biphenyls (PCBs) by river water fish: the case of River Chenab. Sci Total Environ, 450-451, 83-91.

Gao CM, Ding JH, Li SP, et al (2013). Active and passive smoking, and alcohol drinking and breast cancer risk in Chinese women. Asian Pac J Cancer Prev, 14, 993-6.

Lambrechts S, Decloedt J, Neven P (2011). Breast cancer prevention: lifestyle changes and chemoprevention. Acta Clin Belg, 66, 283-92.

Lee SH, Ra JS, Choi JW, et al (2014). Human health risks associated with dietary exposure to persistent organic pollutants (POPs) in river water in Korea. Sci Total Environ, 470-471, 1362-9.

Kim J, Lim SY, Shin A, et al (2009). Fatty fish and fish omega-3 fatty acid intakes decrease the breast cancer risk: a case control study. BMJ Cancer, 9, 216.

Hirose K, Takezaki T, Hamajima N, et al (2003). Dietary factors protective against breast cancer in Japanese premenopausal and postmenopausal women. Int J Cancer, 107, 276-282.

Hirunwatthanakul P, Sriplung H, Geater A (2006). Radiumcontaminated water: a risk factor for cancer of the upper digestive tract. Asian Pac J Cancer Prev, 7, 295-8.

Parkin DM, Bray F, Ferlay J, et al (2005). Global cancer statistics, 2002. CA Cancer J Clin, 55, 74-108.

Sala-Vila A, Calder PC (2011). Update on the relationship of fish intake with prostate, breast, and colorectal cancers. Crit Rev Food Sci Nutr, 51, 855-71.

Terry PD, Rohan TE, Wolk A (2003). Intakes of fish and marine fatty acids and the risks of cancers of the breast and prostate and of other hormone-related cancers: a review of the epidemiologic evidence. Am J Clin Nutr, 77, 532-43.

Wang D, Yu Y, Zhang X, et al (2013). Organochlorine pesticides in fish from Taihu Lake, China, and associated human health risk assessment. Ecotoxicol Environ Saf, 98, 383-9.

Wang YM, Mo BQ, Takezaki T, et al (2003). Geographical variation in nutrient intake between urban and rural areas of Jiangsu province, China and development of a semiquantitative food frequency questionnaire for middle-aged inhabitants. J Epidemiol, 13, 80-9. 
Chang-Ming Gao et al

Watanabe KH, Desimone FW, Thiyagarajah A, et al (2003). Fish tissue quality in the lower mississippi river and health risks from fish consumption. Sci Total Environ, 302, 109-26.

Wirfalt E, Mattisson I, Gullberg B, et al (2002). Postmenopausal breast cancer is associated with high intakes of omega6 fatty acids (Sweden). Cancer Causes Control, 13, 883-93.

Yang L, Parkin DM, Ferlay J, et al (2005). Estimates of Cancer Incidence in China for 2000 and Projections for 2005. Cancer Epidemiol Biomarkers Prev, 14, 243-50.

Yang YX, Wang GY, X.C P (2002) China Food Composition 2002. Pag.311-313. Beijing university medical press, Beijing.

Zheng JS, Hu XJ, Zhao YM, et al (2013). Intake of fish and marine n-3 polyunsaturated fatty acids and risk of breast cancer: meta-analysis of data from 21 independent prospective cohort studies. BMJ, 346, 3706.

Zhuang P, Li ZA, McBride MB, et al (2013). Health risk assessment for consumption of fish originating from ponds near Dabaoshan mine, South China. Environ Sci Pollut Res Int , 20, 5844-54. 